\title{
PECULIARITIES OF PSYCHOMOTOR REACTION OF SCHOOLCHILDREN WITH INTELLECTUAL DISABILITIES: ASPECTS OF MODERATE INTENSITY EXERCISING AND AGE
}

\author{
Dovilè Selickaitė, Diana Rèklaitienė, Jūratė Požèrienė \\ Lithuanian Sports University, Kaunas, Lithuania
}

\begin{abstract}
Background. Intellectual disability is defined as significantly reduced ability to understand new or complex information, to learn and to apply new skills. Integration into the society and independent living for intellectually disabled people is demanding because of slowdown decision processing. Quick enough response time is of vital importance not only for the motor development but also for faster and better adaptation to the changing life conditions.

Methods. The subjects were 112 persons with and without intellectual disability aged 11 to 18 years and recruited for the study. The Reaction Timer RA-1 was used to measure reaction time and to determine the speed characteristics of the person's psychomotor response before and after moderate intensity exercising. Heart rate monitor Polar RS800 was used to measure the person's heart rate.

Results. The best reaction time was demonstrated by 16-year-old normally developed individuals and those with mild intellectual disability $(p<.05)$. The slowest were 11 and 12 -year-old individuals $(p<.05)$. The best reaction time was demonstrated by 14-year-old individuals with moderate intellectual disability and the worst - by 12 and 16 year-old persons with this disability $(p<.05)$.

Conclusion. Moderate-intensity exercising has a positive influence on the execution of the complex reaction task (LRHL). The considerable reaction time increase was observed for individuals with moderate intellectual disability.
\end{abstract}

Keywords: intellectual disability, reaction time, moderate intensity exercising.

\section{INTRODUCTION}

W

orld Health Organization and researchers (Hilgenkamp, van Wijck, \& Evenhuis , 2010; Muijen \& Negru, 2010; Merrill, 2004; Heikura et. al., 2008) define intellectual disability as significantly reduced ability to understand new or complex information, to learn and to apply new skills. It affects the decrease of social functions of those people. The regional Director for Europe of WHO Z. Jacobi (Muijen \& Negru, 2010) states that mentally retarded children and young people should have the same rights to health and social care, to education and security services, as well as their peers. Fredheim, Lien, Danbolt, Kjønsberg, \& Haavet (2011) conducted a study which showed that people with intellectual disabilities exhibited poorer health status which was affected not only by disability, but also by external reasons, such as lack of information, low quality of provided social services, and insufficient level of physical activity. According to Maulik, Mascarenhas, Mathers, Tarun, \& Shekhar (2011), one percent of the world population has intellectual deficiency, which is most prevalent among children and adolescents. Therefore, it is necessary to think seriously about and look for the ways to improve their quality of life and to empower individuals with intellectual disabilities for equal participation in the community and to have active social life. 
Cognitive, psychomotor skills and appropriate behaviour may produce much better outcomes than expected if they receive attention and are actively developed (Song \& An, 2004; McGeown, Johnstone, McKirdy, Owens, \& Stanfield, 2013; de Bildt, Sytema, Kraijer, Sparrow, \& Minderaa, 2005). One of the reasons why the independence and integration into the society of mentally retarded people are complicated is their slow decision making and long information processing time (Standen, Rees, \& Brown, 2009 a; Standen, Karsandas, Anderton, Battersby, \& Brown, 2009 b; Hilgenkamp et al., 2010). Rather short response time is of vital importance not only for their motor development, but also for faster and better adaptation to the changing life conditions. Recently it has been one of the objects that modern scientists are interested in (Weeks, Chua, \& Elliott, 2000; Un \& Erbahceci, 2001, Song \& An, 2004; Merrill, 2004; Vicari, Verucci, \& Carlesimo, 2007; Heath, Grierson, Binsted, \& Elliott, 2007; Carmeli et al., 2008; Rèklaitienè, Selickaite, \& Požèrienè, 2011). Therefore, studies are needed in this area to help with following CNS functional changes in children and adolescents considering age and also the developmental proccess, the impact of adapted training and education measures for people with intelectual disabilites. All this would also contribute to creation and implementation of better social conditions for people with intellectual disabilities and reduce their exclusion in our modern society.

Participants. Biomedical study was conducted with the authorization of Kaunas Regional Biomedical Research Ethics Committee, received permit of the educational institution administration and consent of children's parents/foster parents. The study recruited 112 persons agef 11 to 18 years and divided them into three groups by intellectual disability. Classification of persons as cognitively impaired or not was based on the degree of ID according to Educational Psychological Service: IQ score for mild intellectual disability is $50-69$ and for moderate intellectual disability it is $35-49$. Persons in Group I (persons without intellectual disability) ( $n=37,16$ males and 21 females, mean age $=14.43, S D=2.39)$ were randomly selected from untrained schoolchildren aged 11-18 years in Kaunas, Lithuania. Persons in Group II (mild intellectual disability) $(n=35,14$ males and 21 females, mean age $=14.31, S D=2.31$ ) were randomly selected pupils from special education classes in a special education school and persons in Group III (moderate intellectual disability) ( $n=$ 40, 14 males and 26 females, mean age $=14.50$, $S D=2.32$ ) were randomly selected pupils from developmental education classes in a special education school in Kaunas, Lithuania, with age groups ranging from 4 to 5 subjects.

Intervention. The study consisted of reaction time measurement and heart rate monitoring methods. Reaction Timer RA-1 (JSC Baltec CNC Technologies, Kaunas) was used to measure the person's reaction time to the appearance of red and green light signals and to determine the speed characteristics of person's psychomotor response controlled by the central nervous system. The device was used alongside with the standard personal computer and a special computer program. When measuring the reaction to light, the subject sits in front of the device and presses a button whenever he/ she sees a light signal. The device records the interval of time between the moment when the subject sees the light and he/she presses the button. Reaction time (RT) was measured in milliseconds (ms). RT in simple tasks (simple reaction time (SRT) task)) is measured since the appearance of the green or red light until the respective key is pressed (right click when the green light appears and left click when the red light appears). RT in complex tasks (choice reaction time (CRT) task)) is measured using the randomness factor as the green or red light appears at random: right click at green light and left click at red light. RT is measured since the appearance of the light until the clicking of respective key. Heart rate monitor Polar RS800 was used to measure the person's heart rate at rest. Afterwards, moderate intensity exercising (70 percent of maximum heart rate) was selected and adjusted according to person's age and heart rate at rest.

Design and procedure. Test procedure. Before the start of test each person was introduced with the test design and procedure. Using a pulse meter the heart rate of each person was measured and with respect to the results, the intensity of physical exercising for each person was selected and applied in a test. A test procedure before the moderate-intensity exercising: the person was comfortably seated at the desk holding a finger next to the button that must be pressed as soon as the light comes on. Before the start of the reaction test task a person was given 5 tries. Fifty reaction time tasks were performed after making sure that person understood the testing procedure correctly. The sequence of reaction time tasks: simple reaction time tasks - left hand response 


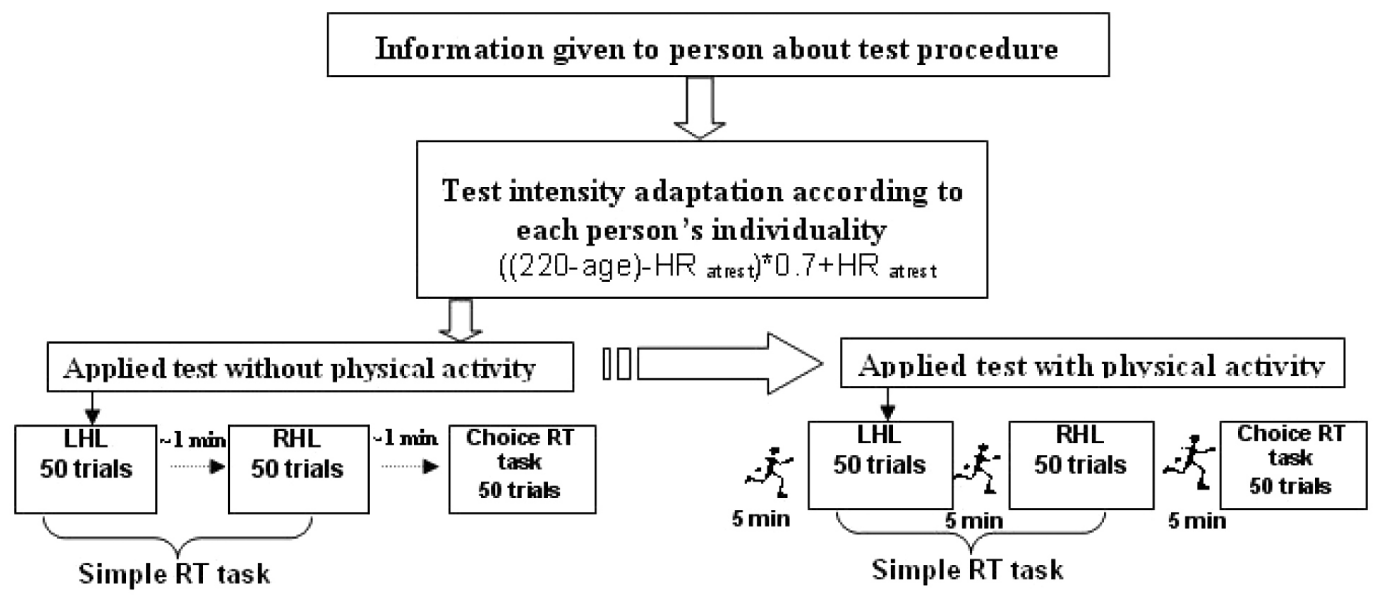

Note. HR - heart rate, LHL - left hand response to light, RHL - right hand response to light, RT - reaction time.

Figure 1. The reaction time test pocedure

to light (LHL), right hand response to light (RHL). Choice reaction time tasks: left - right hand response to light. One minute break was made between separate tasks (Figure 1). The test procedure after moderate intensity exercising: moderate intensity running lasted 5 minutes (moderate intensity exercising for each person was calculated individually according to the formula $\left((220\right.$-age $\left.\left.\left.)-\mathrm{HR}_{\text {at res }}\right)\right) * 0.7+\mathrm{HR}_{\text {at rest }}\right)$. Moderate intensity exercising was followed by 50 reaction-time evaluation tasks (Figure 1). Sequence of reaction time tasks: simple reaction time tasks moderate intensity running, left hand response to light (LHL), moderate intensity running, righthand response to light (RHL), moderate intensity running, left - right hand response to light (choice reaction time task) (Figure 1). Heart rate recovery was monitored after the completion of running tasks and reaction time tasks. Repeated running and next reaction time task was started only when the person's heart rate returned to the level of heart rate at rest.

Statistical analysis. Prior to processing the reaction time data, response times below $100 \mathrm{~ms}$ and above $1000 \mathrm{~ms}$ were rejected. The rejection made up $1.5 \%$. Data were processed using a Statistical Package for the Social Science (SPSS), Version 20.0. The software calculated means of trials, tasks in different intellectual development groups; standard deviation was used in this study as an indicator to evaluate response inconsistency; statistical significance to evaluate the reliability of results. Non-parametric methods were used to determine the statistical significance: MannWhitney $U$ test was used between groups of different age and disability level; Wilcoxon's matched pairs test was used between different tasks. A $p$-value less than .05 was regarded as statistically significant.

\section{RESULTS}

The comparison of normally developed different age subjects revealed that 16-year-old subjects had a faster response rate before and after moderate intensity exercising. Before moderate intensity exercising LHL $\bar{x}=203 \pm 27 \mathrm{~ms}$, RHL $\bar{x}=204 \pm 28 \mathrm{~ms}$, LRHL $\bar{x}=362 \pm 65 \mathrm{~ms}$; after moderate intensity exercising LHL $\bar{x}=229 \pm$ $21 \mathrm{~ms}$, RHL $\bar{x}=238 \pm 26 \mathrm{~ms}$, LRHL $\bar{x}=377 \pm$ $12 \mathrm{~ms}$. The slower reaction before and after moderate intensity exercising was demonstrated by 11-year-old subjects. After moderate intensity exercising LHL $\bar{x}=274 \pm 11 \mathrm{~ms}$, RHL $\bar{x}=283 \pm$ $25 \mathrm{~ms}$, LRHL $\bar{x}=466 \pm 42 \mathrm{~ms}$; before moderate intensity exercising LHL $\bar{x}=327 \pm 12 \mathrm{~ms}$, RHL $\bar{x}=306 \pm 27 \mathrm{~ms}$, LRHL $\bar{x}=511 \pm 62 \mathrm{~ms}$ (Figure 2). Statistically significant difference was found between 11-year-olds' group and all the senior groups $(p=.01)$.

Subjects aged 16 years demonstrated a faster response rate before and after moderate intensity exercising in comparison with all age groups with mild intellectual disability. Before physical activity LHL $\bar{x}=207 \pm 13 \mathrm{~ms}$, RHL $\bar{x}=213 \pm 15 \mathrm{~ms}$, LRHL $\bar{x}=386 \pm 62 \mathrm{~ms}$; after moderate intensity exercising LHL $\bar{x}=217 \pm 20 \mathrm{~ms}$, RHL $\bar{x}=218 \pm$ $52 \mathrm{~ms}$, LRHL $\bar{x}=387 \pm 42 \mathrm{~ms}$, the slowest were 12 -year-old subjects. Before moderate intensity 
exercising LHL $\bar{x}=346 \pm 100 \mathrm{~ms}$, RHL $\bar{x}=343 \pm$ $55 \mathrm{~ms}$, LRHL $\bar{x}=505 \pm 66 \mathrm{~ms}$; after moderate intensity exercising LHL $\bar{x}=369 \pm 78 \mathrm{~ms}$, RHL $\bar{x}=376 \pm 88 \mathrm{~ms}$, LRHL $\bar{x}=524 \pm 80 \mathrm{~ms}$ (Figure 2). Statistically significant differences were found between 11 and 15-16-year-old subjects ( $p=.01$ ), between 12 and $15-16$-year-olds ( $p=.02$ ), between 13 and 16-year-olds $(p=.01)$, between 14 and $15-16$-year-olds $(p=.02)$, between 15 and 16-yearolds $(p=.05)$, between 16 and 17-18-year-olds $(p=.05)$.

Subjects aged 14 years were the fastest with the response in the group of children with moderate intellectual disability. Before moderate intensity exercising LHL $\bar{x}=305 \pm 63 \mathrm{~ms}$, RHL $\bar{x}=343 \pm$ $69 \mathrm{~ms}$, LRHL $\bar{x}=553 \pm 68 \mathrm{~ms}$; after moderateintensity exercising LHL $\bar{x}=337 \pm 72 \mathrm{~ms}$, RHL $\bar{x}=374 \pm 109 \mathrm{~ms}$, LRHL $\bar{x}=528 \pm 52 \mathrm{~ms}$, the slowest were 12-year-old subjects (before moderate intensity exercising LHL $\bar{x}=566 \pm$ $125 \mathrm{~ms}$, RHL $\bar{x}=513 \pm 155 \mathrm{~ms}$, LRHL $\bar{x}=640 \pm$ $110 \mathrm{~ms}$; after moderate intensity exercising LHL $\bar{x}=540 \pm 161 \mathrm{~ms}$, RHL $\bar{x}=512 \pm 116 \mathrm{~ms}$, LRHL $\bar{x}=655 \pm 76 \mathrm{~ms}$,) and subjects 16 years old (before moderate intensity exercising LHL $\bar{x}=576 \pm$ $130 \mathrm{~ms}$, RHL $\bar{x}=519 \pm 141 \mathrm{~ms}$, LRHL $\bar{x}=599 \pm$ $155 \mathrm{~ms}$; after moderate intensity exercising LHL $\bar{x}=570 \pm 138 \mathrm{~ms}$, RHL $\bar{x}=568 \pm 137 \mathrm{~ms}$, LRHL $\bar{x}=613 \pm 133 \mathrm{~ms}$ (Figure 2). Statistically significant difference while executing the task of simple reaction was found between 11-12 and 14-yearold subjects ( $p=.05$ ), between 14 and 16-year-olds $(p=.03)$, between 16 and 17-18-year-olds $(p=.03)$.

The analysis of simple reaction time results (LHL and RHL) revealed that reaction after moderate intensity exercising got slower in all age groups of normally developed subjects (except for subjects 14 and 18 years old). Right hand reaction after moderate intensity exercising was faster than before moderate intensity exercising in the group of 14 and 18-year-old subjects. Choice reaction time task (LRHL) after moderate intensity exercising was executed faster in the group of 12, 17, 18-yearold subjects (Figure 2). Statistically significant differences are illustrated in Table 1.

In the group of 13 and 17-year-old subjects with mild intellectual disability the reaction time with left hand was shorter after moderate intensity exercising then before moderate intensity exercising. 18-year-old subjects' right hand reaction time was better after moderate intensity exercising then before moderate intensity exercising. In all other age groups reaction time with both hands was faster before than after moderate intensity exercising (Figure 2). Statistically significant differences are illustrated in Table 1.

In the group of 11, 12 and 15-year-old subjects with moderate intellectual disability the reaction time with left hand was shorter after moderate intensity exercising then before moderate intensity exercising. While performing the task with right hand the reaction time was better after moderate intensity exercising in the groups of 11, 12, 15 and 17-year-old subjects. Choice reaction time after moderate intensity exercising was faster in the groups of 13,14, 15 and 17-year-old subjects (Figure 2). Statistically significant differences are illustrated in Table 1.

The analysis of simple reaction time results between left and right hand in the groups of normally developed subjects revealed that reaction before moderate intensity exercising in the groups of 11 , $13,14,15$ and 16-year-old subjects was better with the left hand than right. It was different for 12 and 17-year-old subjects, their reactions were better with the right hand. After moderate intensity exercising 13, 15 and 16-year-old subjects were faster with the left hand, while 11, 12, 13, 17 and 18-year-old subjects reacted faster with the right hand. 11, 15, 16 and 18-years old subjects with mild intellectual disability while performing the task before moderate intensity exercising were faster with left hand than with the right one. Other age groups were better with their right hand task. After moderate intensity exercising the subjects aged $12,13,15,16$ and 17 years were faster with the left hand while other age groups were better with the right hand; 13, 14 and 17-year-old subjects with moderate intellectual disability while performing the task before moderate intensity exercising were faster with the left hand then with the right one. After moderate intensity exercising the reaction time with the right hand was shorter in all groups except for 14-year-old subjects (Figure 2). Statistically significant differences are illustrated in Table 1.

The analysis of reaction time between groups with different intellectual disability revealed that normally developed subjects had better reaction time then those with intellectual deficiency. Subjects with mild intellectual disability had better reaction then those with moderate intellectual disability (Figure 2). Statistically significant differences are illustrated in Table 2. 
Table 1. Statistical significance between reaction time tasks

\begin{tabular}{|c|c|c|c|c|c|c|c|c|c|c|}
\hline Test & LHL & re \& & PHA & RHI & ore \& & PHA & LRHL & $\&$ after & $\begin{array}{c}\text { LHL \& RHL } \\
\text { after PHA }\end{array}$ & $\begin{array}{c}\text { LHL \& RHL } \\
\text { after PHA }\end{array}$ \\
\hline Age Group & I & II & III & I & II & III & I & III & III & I \\
\hline 11 & .043 & & & & & & .043 & & & .043 \\
\hline 12 & .043 & & & .043 & & & & & & \\
\hline 14 & & & .043 & & & & & .043 & & \\
\hline 15 & .043 & .043 & & & .043 & & & & & \\
\hline 16 & & & & & & .043 & & & .043 & \\
\hline 17 & .043 & & & & & & & & & \\
\hline
\end{tabular}

Table 2. Statistical significance between groups of subjects with different intellectual disability

\begin{tabular}{|c|c|c|c|c|c|c|c|}
\hline \multirow{2}{*}{ 总 } & & \multicolumn{3}{|c|}{ Before physical activity } & \multicolumn{3}{|c|}{ After physical activity } \\
\hline & Age Test & LHL & RHL & LRHL & LHL & RHL & LRHL \\
\hline \multirow{4}{*}{ 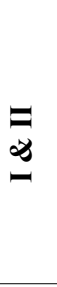 } & 12 & & .03 & .02 & & .05 & .01 \\
\hline & 13 & .03 & .05 & & .05 & .05 & \\
\hline & 14 & & & .02 & & & \\
\hline & 18 & & & .05 & & .01 & .03 \\
\hline \multirow{8}{*}{$\underset{\Xi}{\Xi}$} & 11 & .01 & .01 & & .01 & .05 & \\
\hline & 12 & .01 & .01 & .03 & .03 & .01 & .01 \\
\hline & 13 & .01 & .01 & .01 & .01 & .01 & .05 \\
\hline & 14 & & & .01 & & & \\
\hline & 15 & .01 & .01 & .01 & .03 & & .05 \\
\hline & 16 & .03 & .03 & & .03 & .03 & .03 \\
\hline & 17 & & .01 & .05 & & & .05 \\
\hline & 18 & .05 & .05 & .02 & .03 & .01 & .01 \\
\hline \multirow{7}{*}{ 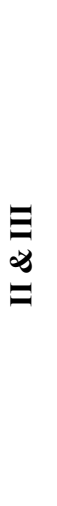 } & 11 & .05 & .01 & & .03 & .05 & \\
\hline & 12 & .03 & & & & & .05 \\
\hline & 13 & & .05 & & & & \\
\hline & 14 & & & .01 & & & \\
\hline & 15 & .01 & .01 & .02 & .03 & & .03 \\
\hline & 16 & .01 & .01 & & .01 & .01 & .05 \\
\hline & 17 & & .03 & & & & \\
\hline
\end{tabular}




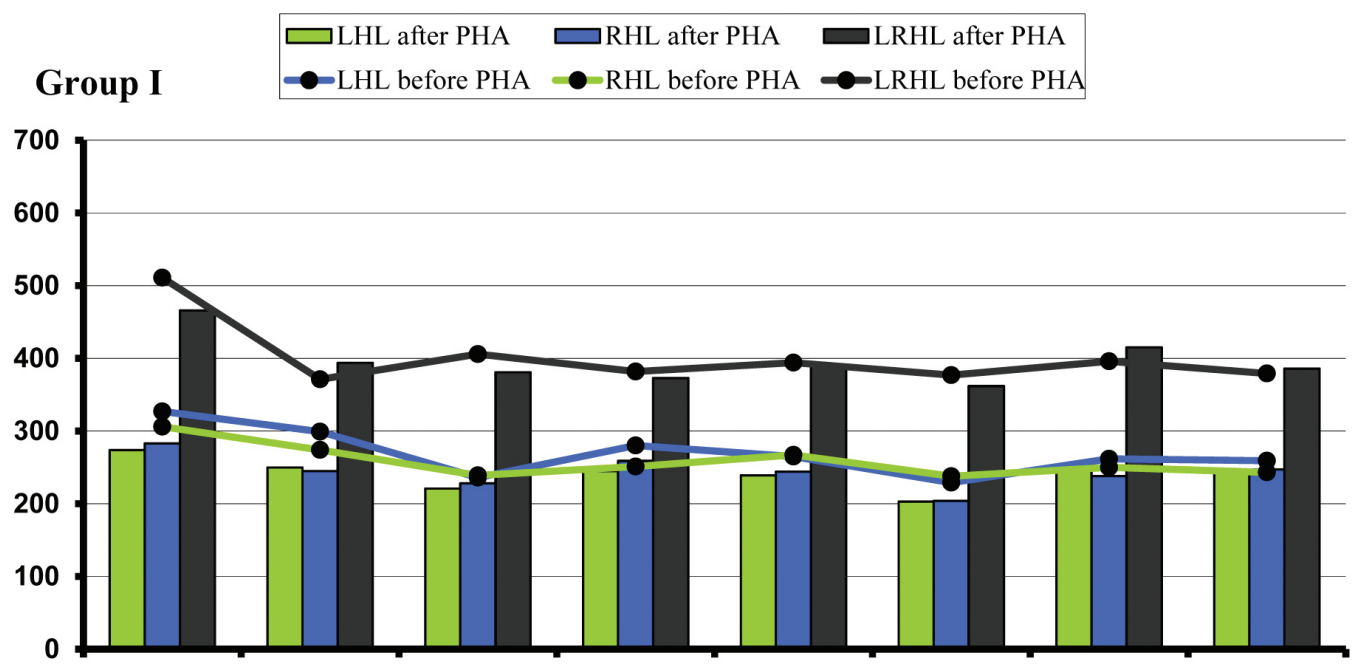

\section{Group II}

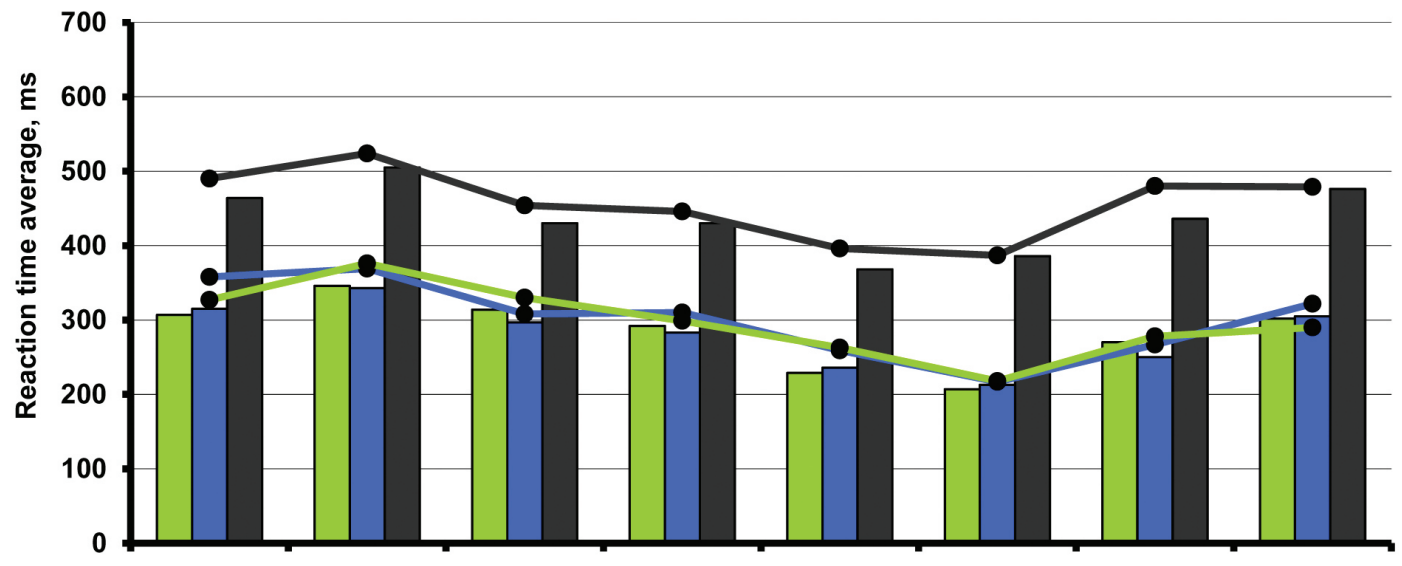

Group III

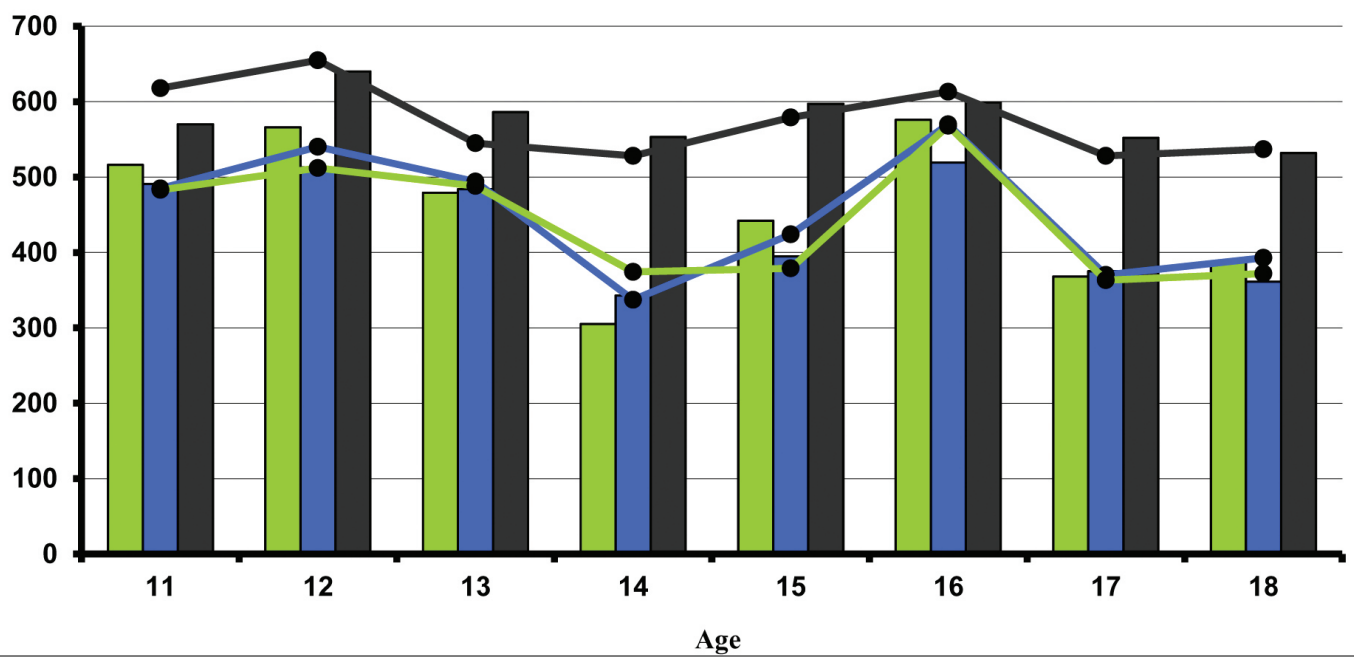

Figure 2. Average reaction time of 11-18 years old subjects 


\section{DISCUSSION}

Scientists studying the dependence of reaction time indicators on age, highlight the significant influence of age and maturation time of CNS structures on reaction time and variability (Rueda, Posner, Rothbart, \& Davis-Stober, 2004; Casey, Tottenham, Liston, \& Durston, 2005; Somerville, Jones, \& Casey, 2010).

The reaction time is used as a primary indicator to assess psychomotor development (Hillman, Weiss, Hagberg, \& Hatfield, 2002). Research by Hillman et al. (2002) showed that motor structures and processes going on in the central nervous system were influenced by exercising. Exercising significantly influenced processes related to movement preparation and response to stimulus (Hillman et al., 2002). Safe environment where thinking processes are trained or educated without fear and negative consequences can help to overcome barriers for better decision-making, and also contributes to the increase of self-confidence and a sense of responsibility (Standen et al., 2009 a; Standen et al., 2009 b; Brown et al., 2011).

Mackey, Hill, Stone, and Bunge (2011) conducted a study with school-age children and the reaction time was used as an indicator to assess the effectiveness of training methodology used. The research showed that velocity of task performance could be trained more through exercising and not so much related to knowledge. The results of our survey partly confirmed this providence indicating that simple and choice reaction tasks were faster executed by the subjects who were physically active in comparison with non-active peers. Hillman, Kramer, Belopolsky, and Smith (2006) investigated the effects of moderate intensity exercising on human cognitive function and found that the simple and complex reaction time tasks were executed faster by physically active than sedentary individuals. Scientists propose that aerobic exercise also has general and specific effect on cognitive function. Although the effect of exercising is observed for most of task execution and cognitive processes, the biggest impact is on those tasks which include executive control processes: planning, accuracy, working memory, interference control, and task coordination. Also scientists believe that exercising makes a significant impact on cognitive processes mostly at a younger age, but for proving this statement more research is needed (Haishi, Okuzumi, \& Kokubun, 2011).
After analysing and comparing the reaction time tasks' results between differently aged groups (11-18 years old) and individuals with different intellectual abilities (normally developed, mild and moderate intellectual disability), it was founded that in the group of normally developed subjects and individuals with mild intellectual disability before moderate intensity exercising, reaction time was shorter while executing the task with the left hand, and after moderate intensity exercising, reaction tasks were faster executed with the right hand. The subjects with moderate intellectual disability were faster while executing reaction tasks with the right hand in both cases - before and after moderate intensity exercising.

According toHeathetal.(2007)whoinvestigated interhemispheric transmission and links, the left hemisphere is responsible for language and intelligence, the right hemisphere is responsible for the elementary skills and callosum is the one which ensures their sustainable action together. Following these findings it can be assumed that in the group of normally developed individuals and subjects with mild intellectual disability, the right hemisphere was more active while executing the task before physical activity, while the left hemisphere, which is more responsible for intellectual abilities, was more active after moderate intensity exercising. In the group of individuals with moderate intellectual impairment, the left hemisphere was more active in both cases: before and after moderate intensity exercising. This shows that the right hemisphere, which is responsible for the implementation of elementary actions, does not work properly and because of that, simple tasks in the central nervous system are transferred as complicated and therefore more time is needed for information processing. Merrill (2004) explains that CNS structures, which are responsible for the automaticity of actions, are slower-maturing for individuals with intellectual deficiencies.

Normally developed individuals demonstrate better results executing all kinds of tasks connected with reaction time in comparison with individuals with mild and moderate intellectual deficiencies, while those with mild deficiency are faster performing the tasks than individuals with moderate intellectual disability (Merrill, 2004; Haishi et al., 2011). Collins and Long (1996), analysing the peculiarities of simple and complex reaction time of individuals with intellectual disabilities, found a significant correlation between reaction time 
and the rate of cognitive dysfunction. Thus, it can be assumed that the reaction time is affected and is reliant on the rate of intellectual disability. These assumptions were also acknowledged by other scientists (Kiuomourtzoglou, Batsiou, Theodorakis, \& Mauromatis, 1994; Weeks et al., 2000; Song \& An, 2004; Vicari et al., 2007; Lahtinen, Rintala, \& Malin, 2007; Carmeli, BarYossef, Ariav, Levy, \& Libermann, 2008; Wuang, Wang, Huang, \& Su, 2008; Jang, Chang, \& Lin, 2009; Lin, Chang, Yeh, \& Meng, 2009; Wuang, Lin, \& Su, 2009 a; Wuang, Wang, Huang, \& Su, 2009 b; Wuang \& Su, 2009; Colom \& Quiroga, 2009; Haishi et al., 2011). The rate of reaction time and standard deviation was found in the group of subjects with cognitive dysfunction (Colom \& Quiroga, 2009). Collins and Long (1996) suggest that dysfunctional intellectual processes which influence cognitive processes cause a lot of problems for sustainable psychological, social and vocational development and improvement. Our study showed that comparing the individuals of different age and rate of intellectual disorder, normally developed individuals had faster reaction and lower response time variability than those with mild and moderate intellectual disability while executing all kinds of reaction tasks before and after physical activity. Individuals with mild intellectual deficiency had better reaction time results and lower response time variability in comparison with individuals with moderate intellectual disability, while executing all kind of reaction tasks before and after exercising (Colom \& Quiroga, 2009; Haishi et al., 2011; Rèklaitienè, Selickaitè, \& Požèrienè, 2012).

Comparing the variability of reaction time results between the left and the right hand it was found that in the group of normally developed subjects variability was higher before moderate intensity exercising while performing the task with the right hand and after moderate intensity exercising variability was higher while performing the task with the left hand. Individuals with mild and moderate intellectual disability demonstrated higher variability of reaction time results in the left hand than in right one in both cases, before and after moderate intensity exercising.

Hultsch and MacDonald (2004) believe that variability of the results while executing the reaction time tasks indicates and reflects the variability of the central nervous system. Referring to this predication, scientists state that in cognitive tasks variability depends on the age, injury, state of health and intellect rate (Collins \& Long, 1996; Hultsch \& MacDonald, 2004; Ram, Rabbitt, Stollery, \& Nesselroade, 2005; Hillman et al., 2006; Bunce, Handley, \& Gaines, 2008; Bunce, MacDonald, \& Hultsch, 2004; Lövdén, Li, Shing, \& Lindenberge, 2007; Robertson, Myerson, \& Hale, 2006; Colom \& Quiroga, 2009). According to Kennedy, Partridge, \& Raz (2008), cognitive function could be influenced by many factors, such as physical and mental health, environmental changes, social environment, motivation, educational level. Bunce et al. (2008) consider that variability of the results while executing the reaction time tasks could be determined by impaired functioning of neurobiological mechanism and dysfunction of the central nervous system. Scientists who conducted studies using magnetic resonance method found that increased variability was due to frontal cortex impairment (Bunce et al., 2008). Bunce et al. $(2004,2008)$ and Haishi et al. (2011) observed that higher variability of tasks' results was influenced by slower reaction time, while reaction time instability depended on attention and executive control volatility. Also variability of reaction tasks' results depended on the complexity of reaction time task and fatigue (Bunce et al., 2004; McLaughlin, Borrie, \& Murthal, 2010). The meta-analysis of research recently conducted in this area suggests that variability of reaction time tasks' results is influenced by age, mental development and the complexity of the task (Hultsch \& MacDonald, 2004; Ram et al., 2005; Bunce et al., 2008; Lövdén et al., 2007; Rẻklaitenè, Selickaitè, \& Požėrienè, 2010, 2011, 2012; Haishi et al., 2011), personal physical and mental health; individuals having any kind of dysfunction and lower rates in cognitive tasks demonstrate higher variability of the results than the healthy ones (Ram et al., 2005; Bunce et al., 2008; Haishi et al., 2011).

Reaction time data analysis showed that there were differences between the groups of different age and intelectual deficiency. It means that creation and development of motor programs is dinamic process, anda particular prefrontal cortex is more activated during it (Weeks et al., 2000; Casey, Tottenham, Liston, \& Durston, 2001; Song \& An, 2004; Rueda et al., 2004; Mohr \& Nagel, 2010; Ghisletta, Kennedy, Rodrigue, Lindenberger, \& Raz, 2010). This explains the fact that at a younger age reaction time is more variable and longer and the maturation of prefrontal cortex influences the development of strategic thinking and in the sequel 
the complex tasks are changed from automatic processes to controlled processes (Casey et al., 2005; Schlaghecken \& Sisman, 2006). Automatic processes develop earlier than controlled processes (Schlaghecken \& Sisman, 2006).

\section{CONCLUSIONS}

The best reaction time was demonstrated by 16 -year-old normally developed individuals and those with mild intellectual disability. The slowest were 11 and 12-year-old individuals. The best reaction time was demonstrated by 14 -year-old individuals with moderate intellectual disability and the worst - by 12 and 16 year-old persons with this disability. Moderate intensity exercising has a positive effect on the execution of the complex reaction task (LRHL). The considerable longer reaction time is typical of the cohort with moderate intellectual disability.

\section{REFERENCES}

Brown, D. J., McHugh, D., Standen, P., Evett, L., Shopland, N., \& Battersby, S. (2011). Designing location-based learning experiences for people with intellectual disabilities and additional sensory impairments. Computers \& Education, 56(1), 11-20. doi:10.1016/j.compedu.2010.04.014

Bunce, D., Handley, R., \& Gaines, S. O. (2008). Depression, anxiety, and within-person variability in adults aged 18 to 85 years. Psychology and Aging, 23(4), 848-858. doi: 10.1037/a00136784

Bunce, D., MacDonald, S. W. S., \& Hultsch, D. F. (2004). Inconsistency in serial choice decision and motor reaction times dissociate in younger and older adults. Brain and Cognition, 56 (3), 320-327. doi: 10.1016/j. bandc.2004.08.006

Carmeli, E., Bar-Yossef, T., Ariav, C., Levy, R., \& Libermann, D. G. (2008). Perceptual - motor coordination in persons with mild intellectual disability. Disability \& Rehabilitation, 30(5), 323-329. Retrieved from http://web.b.ebscohost.com/ehost/pdfviewer/ pdfviewer?sid=60358ecf-a54c-4306-beda-7a692e4a07f b\%40sessionmgr110\&vid $=40$ \&hid $=114$

Carmeli, E., Bar-Yossef, T., Ariav, C., Paz, R., Sabbag, H., \& Levy, R. (2008). Sensorimotor impairments and strategies in adults with intellectual disabilities. Motor Control, 12(4), 348-361. Retrieved from http://web.b.ebscohost.com/ehost/pdfviewer/ pdfviewer?sid=60358ecf-a54c-4306-beda-7a692e4a07f b\%40sessionmgr110\&vid=35\&hid $=114$

Casey, B. J., Durston, S., \& Fossella, J. A. (2001). Evidence for a mechanistic model of cognitive control. Clinical Neuroscience Research, 1, 267-282. doi:10.1016/S1566-2772(01)00013-5

Casey, B. J., Tottenham, N., Liston, C., \& Durston, S. (2005). Imaging the developing brain: What have we learned about cognitive development? Trends in Cognitive Sciences, 9(3), 104-109. doi: 10.1016/j. tics.2005.01.011

Collins, L. F., \& Long, Ch. J. (1996). Visual reaction time and its relationship to neuropsychological test performance. Archives of Clinical Neuropsychology, 11(7), 613-623. doi: 10.1016/0887-6177(97)81255-3
Colom, R., \& Quiroga, M. Á. (2009). Neuroticism, intelligence, and intra-individual variability in elementary cognitive tasks: Testing the mental noise hypothesis. Psicothema, 21(3), 403-408. Retrieved from http://web.b.ebscohost.com/ehost/pdfviewer/ pdfviewer?sid=1fc1d63e-aa90-440e-be1b-21d93861e5 a9\%40sessionmgr114\&vid $=5 \&$ hid $=113$

De Bildt, A., Sytema, S., Kraijer, D., Sparrow, S., \& Minderaa, R. (2005), Adaptive functioning and behaviour problems in relation to level of education in children and adolescents with intellectual disability. Journal of Intellectual Disability Research, 49(9), 672681. doi: 10.1111/j.1365-2788.2005.00711.x

Fredheim, T., Lien, L., Danbolt, L. J., Kjønsberg, K., \& Haavet, O. R. (2011). Experiences with general practitioners described by families of children with intellectual disabilities and challenging behaviour: A qualitative study. BMJ Open, 1(2). doi: 10.1136/ bmjopen-2011-000304

Ghisletta, P., Kennedy, K. M., Rodrigue, K. M., Lindenberger, U., \& Raz, N. (2010). Adult age differences and the role of cognitive resources in perceptual-motor skill acquisition: Application of a multilevel negative exponential model. Journal of Gerontology: Psychological Sciences, 65B(2), 163-173. doi: 10.1093/geronb/gbp126.

Haishi, K., Okuzumi, H., \& Kokubun, M. (2011). Effects of age, intelligence and executive control function on saccadic reaction time in persons with intellectual disabilities. Research in Developmental Disabilities, 32, 2644-2650. doi: 10.1016/j.ridd.2011.06.009

Heath, M., Grierson, L., Binsted, G., \& Elliott, D. (2007). Interhemispheric transmission time in persons with Down syndrome. Journal of Intellect Disability Research, 51(12), 972-981. doi: 0.1111/j.13652788.2007.01009.x

Heikura, U., Taanila, A., Hartikainen, A. L., Olsen, P., Linna, S. L., Wendt, L., \& Järvelin, M. R. (2008). Variations in prenatal sociodemographic factors associated with intellectual disability: A study of the 20-year interval between two birth cohorts in northern Finland. American Journal of Epidemiology, 167(2), 169-177. 
Hilgenkamp, T. I. M., van Wijck, R., \& Evenhuis, H. M. (2010). Physical fitness in older people with ID-Concept and measuring instruments: A review. Research in Developmental Disabilities, 31, 1027-1038. doi: 10.1016/j.ridd.2010.04.012

Hillman, Ch. H., Kramer, A. F., Belopolsky, A. V., \& Smith, D. P. (2006). A cross-sectional examination of age and physical activity on performance and eventrelated brain potentials in a task switching paradigm. International Journal of Psychophysiology, 59, 30-39.

Hillman, Ch. H., Weiss, E. P., Hagberg, J. M., \& Hatfield, B. D. (2002). The relationship of age and cardiovascular fitness to cognitive and motor processes. Psychophysiology, 39, 303-312. doi: 1O.IOI7.S(K)485772OI393058

Hultsch, D. F., \& MacDonald, S. W. S. (2004). Intraindividual variability in performance as a theoretical window onto cognitive aging. In R. A. Dixon, L. Bäckman, \& L.-G. Nilsson (Eds.), New frontiers in cognitive aging (pp. 65-88). Oxford: Oxford University Press.

Jang, Y., Chang, T. C., \& Lin, K. C. (2009). Reliability and validity of a physical capacity evaluation used to assess individuals with intellectual disabilities and mental illness. International Journal of Rehabilitation Research, 32(1), 77-84. doi: 10.1097/MRR.0b013e32830f912f

Kennedy, K. M., Partridge, T., \& Raz, N. (2008). Age-related differences in acquisition of perceptualmotor skills: Working memory as a mediator. Aging, Neuropsychology, \& Cognition, 15, 165-183. doi: $10.1080 / 13825580601186650$

Kioumourtzoglou, E., Batsiou, S., Theodorakis, Y., \& Mauromatis, G. (1994). Selected motor skills of mentally retarded and no retarded individuals. Perceptual Motor Skills, 78(3), 1011-1015.

Lahtinen, U., Rintala, P., \& Malin, A. (2007). Physical performance of individuals with intellectual disability: 030 years follows up. Adapted Physical Activity Quarterly, 24(2), 125-143.

Lin, Y. L., Chang, Y. T., Yeh, C. C., \& Meng, L. F. (2009). The performance of mouse pointing and selecting for pupils with and without intellectual disabilities. Research in Developmental Disabilities, 30(6), 11881195. doi: 10.1016/j.ridd.2009.03.006

Lövdén, M., Li, S., Shing, Y. L., \& Lindenberger, U. (2007). Within-person trial-to-trial variability precedes and predicts cognitive decline in old and very old age: Longitudinal data from the Berlin Aging Study. Neuropsychologia, 45, 2827-2838.

Mackey, A. P., Hill, S. S., Stone, S. I., \& Bunge, S. A. (2011). Differential effects of reasoning and speed training in children. Developmental Science, 14(3), 582590. doi: 10.1111/j.1467-7687.2010.01005.x

Maulik, P. K., Mascarenhas, M. N., Mathers, C. D., Tarun, D., \& Shekhar, S. (2011). Prevalence of intellectual disability: A meta-analysis of populationbased studies. Research in Developmental Disabilities, 2(32), 419-436. doi: 10.1016/j.ridd.2010.12.018
McGeown, H. R., Johnstone, E. C., McKirdy, J., Owens, D. C., \& Stanfield, A. C. (2013). Determinants of adult functional outcome in adolescents receiving special educational assistance. Journal of Intellectual Disability Research, 57(8), 766-733. doi: 10.1111/j.13652788.2011.01533.x

McLaughlin, P. M., Borrie, M. J., \& Murthal, S. J. E. (2010). Shifting efficacy, distribution of attention and controlled processing in two subtypes of mild cognitive impairment: Response time performance and intraindividual variability on a visual search task. Neurocase, 16(5), 408-417. doi: $10.1080 / 13554791003620306$

Merrill, E. C. (2004). Consistent mapping and automatic visual search: Comparing persons with and without intellectual disability. Journal of Intellectual Disability Research, 48(8), 746-753. doi: 10.1111/j.13652788.2004.00594.x

Mohr, P. N. C., \& Nagel, I. E. (2010). Variability in brain activity as an individual difference measure in neuroscience? The Journal of Neuroscience, 30(23), 7755-7757. doi: 10.1523/JNEUROSCI.1560-10.2010

Muijen, M., \& Negru, L. (2010). Landmark declaration signed on the health of children with intellectual disabilities. Retrieved from http://www.euro.who.int/en/ what-we-publish/information-for-the-media/sections/ latest-press-releases/landmark-declaration-signed-onthe-health-of-children-with-intellectual-disabilities.

Ram, N., Rabbitt, P., Stollery, B., \& Nesselroade, J. R. (2005). Cognitive performance inconsistency: intraindividual change and variability. Psychology \& Aging, 20(4), 623-633. doi: 10.1037/0882-7974.20.4.623

Rèklaitienè, D., Selickaitè, D., \& Požėrienè, J. (2011). Psychomotor reaction of persons with intellectual disabilities [Abstract]. Book of Abstracts, 18th ISAPA Paris, France, 4-8 July 2011, ISAPA/ICSSPE. Paris: University Paris West Nanterre La Defence, P. 241.

Rèklaitienè, D., Selickaitė, D., \& Požėrienè, J. (2010). Sutrikusio intelekto asmenu psichomotorinès reakcijos ypatumai. Ugdymas. Kūno kultūra. Sportas, 3(78), 83-89.

Rèklaitienè, D., Selickaitè, D., \& Požėrienè, J. (2012). The influence of moderate physical load on psychomotor reaction of persons with intellectual disabilities. EUCAPA 2012: European Congress of Adapted Physical Activity. Book of Abstracts, Tralee, Kerry, Ireland, May 6-8, 2012. Tralee: Institute of Technology Tralee. P. 1.

Robertson, S., Myerson, J., \& Hale, S. (2006). Are there age differences in intraindividual variability in working memory performance? Journal of Gerontology, 61B(1), $18-24$.

Rueda, M. R., Posner, M. I., Rothbart, M. K., \& DavisStober, C. P. (2004). Development of the time course for processing conflict: An event-related potentials study with 4 year olds and adults. BMC Neuroscience, 39(5), 1-13. doi: 10.1186/1471-2202-5-39

Schlaghecken, F., \& Sisman, R. (2006). Low-level motor inhibition in children: Evidence from the negative 
compatibility effect. Advances in Cognitive Psychology, 2(1), 7-19. doi: 10.2478/v10053-008-0041-0

Somerville, L. H., Jones, R. M., \& Casey, B. J. (2010). A time of change: Behavioral and neural correlates of adolescent sensitivity to appetitive and aversive environmental cues. Brain and Cognition, 72, 124-133. doi: 10.1016/j.bandc.2009.07.003

Standen, P. J., Karsandas, R. B., Anderton, N., Battersby, S., \& Brown, D. J. (2009 b). An evaluation of the use of a computer game in improving the choice reaction time of adults with intellectual disabilities. Journal of Assistive Technologies, 3(4), 4-11. Retrieved from https://www.ntu.ac.uk/cels/he_projects/projects/ other_projects/interactive technologies/85312.pdf

Standen, P. J., Rees, F. \& Brown, D. J. (2009 a). Effect of playing computer games on decision making in people with intellectual disabilities. Journal of Assistive Technologies, 3(2), 6-14. Retrieved from http://www. icdvrat.reading.ac.uk/2008/papers/ICDVRAT2008 S01_N01_Standen_Rees_Brown.pdf

Song, K. Y., \& An, J. D. (2004). Premotor and motor reaction time of educable mentally retarded youths in a Taekwondo program. Perceptual Motor Skills, 99(2), 711-723.

Un, N., \& Erbahçeci, F. (2001). The evaluation of reaction time on mentally retarded children. Pediatric Rehabilitation, 4(1), 17-20. Retrieved from http://web.b.ebscohost.com/ehost/pdfviewer/ pdfviewer?sid=1 fc1d63e-aa90-440e-be1b-21d93861e5 a9\%40sessionmgr114\&vid=127\&hid $=113$
Vicari, S., Verucci, L., \& Carlesimo, G. A. (2007). Implicit memory is independent from IQ and age but not from etiology: Evidence from Down and Williams. Journal of Intellectual Disability Research, 51(12), 932-941. doi: 10.1111/j.1365-2788.2007.01003.x

Weeks, D. J., Chua, R., \& Elliott, D. (2000). Perceptualmotor behavior in Down Syndrome. Human Kinetics.

Wuang, Y. P., Lin, Y. H., \& Su, C. Y. (2009 a). Rash analysis of the Bruininks - Oseretsky Test of Motor Proficiency - second edition in intellectual disabilities. Research in Developmental Disabilities, 3(6), 11321044. doi: 10.1016/j.ridd.2009.03.003

Wuang, Y. P., Su, C. Y. (2009). Rash analysis of the Developmental Test of Visual - Motor Integration in children with intellectual disabilities. Research in Developmental Disabilities, 30(5), 1044-1053. doi: 10.1016/j.ridd.2009.02.007

Wuang, Y. P., Wang, C. C., Huang, M. H., \& Su, C. Y. (2008). Profiles and cognitive predictors of motor functions among early school - age children with mild intellectual disabilities. Journal of Intellectual Disability Research, 52(12), 1048-1060. doi: 10.1111/j.13652788.2008.01096.x

Wuang, Y. P., Wang, C. C., Huang, M. H., \& Su, C. Y. (2009 b). Prospective study of the effect of sensory integration, neurodevelopmental treatment, and perceptual - motor therapy on the sensorimotor performance in children with mild mental retardation. The American Journal of Occupational Therapy, 63(4), 441-452.
Corresponding author Diana Rèklaitienè Lithuanian Sports University Sporto str. 6, LT-44221 Kaunas Lithuania Tel. +370 373026 60, +37069824568 Email diana.reklaitiene@1su.1t 